\title{
Aluminum tanning of hide powder and skin pieces under microwave irradiation
}

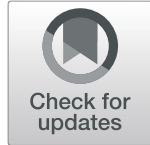

Yue Liu ${ }^{1,2}$, Bin Song ${ }^{1,2}$, Jinwei Zhang ${ }^{1,2}$, Carmen Gaidau ${ }^{3}$ and Haibin Gu ${ }^{1,2^{*}}$

\begin{abstract}
The application and mechanism study of microwave irradiation in traditional industries have attracted considerable attention owing to the unique thermal and athermal effects that could lead to unexpected benefits in high-efficiency and clean production. Herein, we report the investigation of the aluminum tanning under microwave irradiation upon using hide powder and skin pieces, respectively, as simulants of real hide or skin. The aluminum tanning process and the tanned products under microwave heating $(\mathrm{MWH})$ were studied and compared with those of conventional water bath heating (WBH) as the controls. For the tanning system of hide powder, the tanning effluents were analyzed in terms of $\mathrm{pH}$, conductivity, dielectric constant and aluminum content, and the tanned powder was investigated by differential scanning calorimetry (DSC), thermogravimetric (TG) analysis, and FT-IR spectroscopy. For the skin piece system, the pH and aluminum content of tanning effluents were also determined, and at the same time, DSC, TG, SEM, FT-IR and shrinkage temperature were used to illustrate the actions of microwaves on the structure and properties of the tanned pieces. The results show that aluminum reactivity in the penetration and binding process of collagen fibers in hide powder and skin pieces improved using microwave treatment. The residual aluminum content was greatly reduced by microwave heating action, and the increased amount of aluminum with evener distribution was observed in the tanned products. Microwave irradiation also resulted in the tanned products with better thermal stability and thermal decomposition resistance. This work further promotes application of microwave treatments for aluminumbased tanning in leather industry.
\end{abstract}

Keywords: Microwave, Aluminum tanning, Hide powder, Skin pieces, Thermal effect, Non-thermal effect

\section{Introduction}

Tanning is regarded as the most crucial process for converting raw hide (or skin) into leather through crosslinking reactions between the reactive groups of collagen fibers and tanning agents, and this process improves the thermal and structural stability of hide collagen matrix [1]. Notably, the tanning process is a complex chemical reaction process that is often carried out upon heating. Thus, it is possible to apply microwave irradiation during the tanning period as a heating source. Microwave is an electromagnetic wave showing a frequency range of 300-300,

\footnotetext{
* Correspondence: guhaibinkong@126.com

'Key Laboratory of Leather Chemistry and Engineering of Ministry of

Education, Sichuan University, Chengdu 610065, China

${ }^{2}$ National Engineering Research Center of Clean Technology in Leather

Industry, Sichuan University, Chengdu 610065, China

Full list of author information is available at the end of the article
}

$000 \mathrm{MHz}$ [2]. It has various advantages such as energy saving, even heating and accelerating reaction rate because of its unique physical, chemical and biological effects [3-10], and it has been widely used in many fields of industry, agriculture, military and communication [11]. Microwave irradiation presents not only thermal effect to increase the temperature of the tanning system, but also a non-thermal effect that is favorable for application to chrome tanning [12-17], vegetable tanning [18, 19], zirconium tanning [20], titanium tanning [21] and aldehyde tanning [22-25]. For example, Costa et al. [17] found that the reaction between Cr (III) and ethylenediaminetetraacetic acid was accelerated upon introduction of microwaves to form purple complexes. Chen et al. $[13,14]$ investigated the action of microwave irradiation on the stability of $\mathrm{Cr}$ (III) complexes using UV-visible spectrophotometry. It was found that carboxyl-containing ligands reacted with the nitrate 
and sulfate groups of $\mathrm{Cr}$ (III) salts to produce different types of $\mathrm{Cr}$ (III) complex products. They found that, under microwaves, the reaction rate and chelate stability of $\mathrm{Cr}$ (III) complexes were greatly improved, indicating that microwaves promote multinuclear coordination of $\mathrm{Cr}$ (III) and hide collagen fibers. Furthermore, Wu et al. [18] studied the binding properties of tannin extract with collagen fibers using microwave as heating sources. The thermal stability of leather was improved under microwave irradiation. Compared to heating using a water bath, the shrinking temperature was increased by about $1{ }^{\circ} \mathrm{C}$, and the content of macromolecular tannin and phenol components in the tanning liquid was decreased. The investigations of these authors confirm that microwave heating promotes the penetration of plant tannins into the skin and the binding to collagen fibers.

Aluminum tanning is also an important tanning method, and it has been used to develop chrome-free tanning systems. Its operation is similar to chrome tanning [26], and the development of new aluminum tanning agents and aluminum-based tanning methods has attracted considerable attention [27, 28]. At present, the main methods of modification of aluminum tanning are developing new coordination groups [29-32] and combination with other tanning methods [33-36]. Notably, microwave irradiation was also investigated for its application in the aluminum tanning process owing to its unique thermal and athermal effects [37, 38]. In our previous work, the microwave-heated hydrolysis and olation behavior of aluminum sulfate [37] and their crosslinking reactions with collagen [38] were studied in the homogeneous system. These investigations confirm the great advantage and potential of microwave heating in aluminum tanning, but the actual aluminum tanning process that is carried out in the heterogeneous system has not yet been covered. Actual aluminum tanning is a material-exchange reaction between aluminum complexes in solution and solid hides, and the tanning process also involves penetrating and binding actions of aluminum tanning agent in the collagen fiber matrix [1]. Therefore, in this paper, the use of hide powder and skin pieces is presented as a research goal to simulate actual aluminum tanning. Hide powder is a flocculent powder obtained from a series of processes such as liming, deliming, demineralizing, buffering, dewatering and pulverizing using raw hide as the starting material [39]. Because the fiber is relatively homogeneous and there is no difference in position, hide powder is often used as a standard reagent for the analysis of tannin content in tannin [40]. However, there is no complex spatial weaving structure of collagen fibers in hide powder. The bundles are in a separated state and cannot accurately reflect the penetration and binding process of aluminum to collagen fibers. Thus, skin pieces were further used to deeply investigate the action of microwave on aluminum tanning. Overall, in the present work, microwave heating $(\mathrm{MWH})$ was applied to the aluminum tanning of hide powder and skin pieces, and the corresponding tanning experiments under water bath heating (WBH) were regarded as controls, as shown in Scheme 1. For the tanning system of hide powder, the tanning effluents were analyzed in terms of $\mathrm{pH}$, conductivity, dielectric constant and aluminum content, and the obtained tanned powder was analyzed by differential scanning calorimetry (DSC), thermogravimetric (TG) analysis, and FT-IR methods. For the skin piece system, the $\mathrm{pH}$ and aluminum content of tanning effluents were also determined, and at the same time, DSC, TG, SEM, FT-IR and shrinkage temperature $\left(T_{s}\right)$ were used to illustrate the action of microwave on the structure and properties of tanned pieces. These analysis methods present a great benefit to provide information on aluminum tanning towards cleaning production and better leather performance with microwaves.

\section{Experimental}

\subsection{Materials}

White hide powder was provided by the Institute of Chemical Industry of Forest Products, Academy of Forestry, China. Pickled goatskin with average area of 4-5 square meters was used for the tanning processing. $\mathrm{Al}_{2}\left(\mathrm{SO}_{4}\right)_{3} \cdot 18 \mathrm{H}_{2} \mathrm{O}$ was purchased from the Aladdin Reagent Company (Shanghai, China). All the other chemicals used were analytical reagent, commercially purchased and used without further treatment.

\subsection{Aluminum tanning of hide powder}

Seventy grams of $\mathrm{NaCl}$ was dissolved in $1000 \mathrm{~mL}$ of distilled water to prepare the $\mathrm{NaCl}$ solution $(70 \mathrm{~g} / \mathrm{L})$ as the solvent for the tanning agent. The aluminum tanning agent was prepared by dissolving $3.265 \mathrm{~g}$ of $\mathrm{Al}_{2}\left(\mathrm{SO}_{4}\right)_{3} \cdot 18 \mathrm{H}_{2} \mathrm{O}$ in $50 \mathrm{~mL}$ of the above $\mathrm{NaCl}$ solvent, and its $\mathrm{pH}$ was determined to be 2.20. $\mathrm{NaHCO}_{3}(1.2346 \mathrm{~g})$ was added to the above solvent (molar ratio of $\mathrm{Al}^{3+}$ to $\mathrm{HCO}_{3}^{-}: 1: 1.5$ ). White hide powder $(5.0 \mathrm{~g})$ and the above $\mathrm{NaCl}$ solution $(50 \mathrm{~mL})$ were added in a conical flask $(250 \mathrm{~mL})$, and the obtained mixture was shaken vigorously for $30 \mathrm{~min}$ at room temperature (RT) at about $25^{\circ} \mathrm{C}$. Then, $50 \mathrm{~mL}$ of aluminum tanning agent was added to $\tan$ the hide powder. The microwave samples were placed in a microwave reactor (Xian Yuhui MCR-3 microwave chemical reactor, China), while the controls were heated in a water bath shaker. Aluminum tanning was conducted for $30 \mathrm{~min}$ at 30,40 and $50^{\circ} \mathrm{C}$, respectively. All the tanning systems were then basified by slowly adding $20 \mathrm{~mL}$ of $\mathrm{NaHCO}_{3}$ solution $(61.73 \mathrm{~g} / \mathrm{L})$. After that, all the microwave and control samples were further treated for $30 \mathrm{~min}$ at 30,40 and $50^{\circ} \mathrm{C}$, respectively. The tanning effluent was collected by filtration for further analysis, and the tanned hide powder was obtained and dried in a freeze dryer. 


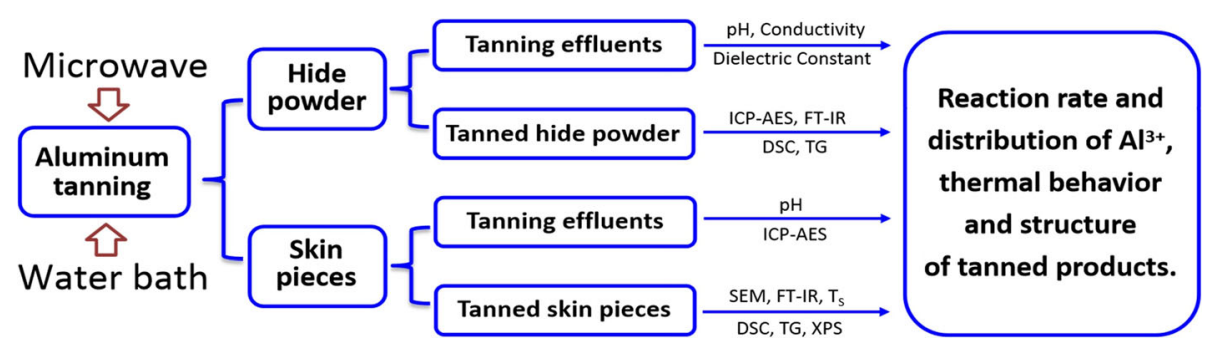

Scheme 1 Flow chart of experiment

\subsection{Aluminum tanning of goatskin pieces}

The $\mathrm{NaCl}$ solution $(100 \mathrm{~g} / \mathrm{L})$ was prepared and used as solvent for the tanning agent. $\mathrm{Al}_{2}\left(\mathrm{SO}_{4}\right)_{3} \cdot 18 \mathrm{H}_{2} \mathrm{O}(194.7 \mathrm{~g})$ was dissolved in the $\mathrm{NaCl}$ solution $(1.0 \mathrm{~L})$ to prepare the aluminum tanning agent with the concentration of 100 $\mathrm{g} / \mathrm{L}$. Skin pieces $(2 \mathrm{~cm} \times 6 \mathrm{~cm})$ were prepared by symmetrically cutting the pickled goatskin along its back line. Each skin piece $(50 \pm 1 \mathrm{~g})$ was soaked in $500 \mathrm{~mL}$ of the aluminum tanning agent in a beaker $(1000 \mathrm{~mL})$. The microwave samples were stirred at $40^{\circ} \mathrm{C}$ in the microwave reactor, while the controls were placed in a water bath shaker at $40^{\circ} \mathrm{C}$. The total tanning time was $10 \mathrm{~h}$, and the $\mathrm{pH}$ values of all the tanning systems were determined every hour. After $5 \mathrm{~h}$, the basifying treatment was conducted by adding $1 \mathrm{~g}$ of $\mathrm{NaHCO}_{3}$ into the beakers. The interval of basifying is $1 \mathrm{~h}$, and this treatment was carried out altogether five times. After $10 \mathrm{~h}$, all the tanning effluents and tanned skin pieces were collected and kept for further analysis.

\subsection{Analysis of tanning effluent, tanned hide powder and skin pieces}

A PHS-3C pH meter (Shanghai Leici Instrument Factory, China) was adopted to measure the $\mathrm{pH}$ values of tanning liquors. A DDS-307 conductivity meter (Shanghai Leici Instrument Factory, China) was used to determine the electrical conductivity of tanning liquor. The dielectric constant was recorded using a dielectric constant meter (DZJC, Nanjing Dasha Mechanical and Electrical Technology Institute, China). The inductively coupled plasma atomic emission spectrometer (ICP-AES, Optima 2100, Perkin-Elmer, USA) was applied to determine the aluminum content of tanning effluent and tanned samples. DSC measurements were carried out under $\mathrm{N}_{2}$ atmosphere on a differential scanning calorimeter (DSC200 PC, Netzsch, Germany). The determined temperature range was $30-200^{\circ} \mathrm{C}$ with a heating rate of $10^{\circ} \mathrm{C} / \mathrm{min}$. TG analysis was carried out under $\mathrm{N}_{2}$ atmosphere using a TGA/DSC Mettler Toledo (Switzerland). The determined temperature range was $50-700^{\circ} \mathrm{C}$ with a heating rate of $10{ }^{\circ} \mathrm{C} / \mathrm{min}$. The shrinkage temperature $\left(\mathrm{T}_{\mathrm{s}}\right)$ was measured on MSW-YD4 (Shanxi, China). The heating medium was water, and the heating rate was $2-3{ }^{\circ} \mathrm{C} / \mathrm{min}$ from room temperature (RT, $25^{\circ} \mathrm{C}$ or so). The infrared spectra were measured on a Fourier transform infrared spectrometer (Nicolet iS10, Thermo Scientific, USA) in the range of $400-4000 \mathrm{~cm}^{-1}$. SEM determination was conducted on a scanning electron microscope (JSM-7500F, JEOL, Japan), and the distribution of aluminum element in the samples was scanned at the same time by the coupled energy dispersive X-ray spectroscopy (EDX) detector. The surfaces of cut skin pieces were coated with gold before SEM observations. X-ray photoelectron spectroscopy (XPS) measurements were conducted on SXAM-800 (Kratos, UK) to determine the characteristic signals of $\mathrm{C}, \mathrm{O}, \mathrm{N}$ and $\mathrm{Al}$ elements. The conditions for XPS are: radiation source of $\mathrm{Al}$ $\mathrm{K} \alpha$, energy range of $-5-1200 \mathrm{eV}$, illuminance area of $300 \mu \mathrm{m} \times 700 \mu \mathrm{m}$, tube voltage of $15 \mathrm{kv}$ and tube current of $10 \mathrm{~mA}$.

\section{Results and discussion}

\subsection{Effect of microwave irradiation on the aluminum tanning of hide powder}

\subsubsection{Analysis of tanning effluents}

During the aluminum tanning process, the hydrolysis and olation of aluminum complexes take place, which leads to the increase of hydrogen ion $\left(\mathrm{H}^{+}\right)$and free charged ions in the tanning system, resulting of uneven charge distribution in the complex molecules [1]. These characteristic changes were characterized by detecting the $\mathrm{pH}$, conductivity, dielectric constant and aluminum content in the aluminum tanning effluent [37]. As shown in Table 1 , the $\mathrm{pH}$ values of tanning effluents at $30-50^{\circ} \mathrm{C}$ under microwave heating $(\mathrm{MWH})$ were measured and compared with those treated by water bath heating (WBH). As expected, with the increase of the reaction temperature, the decreased tendency of $\mathrm{pH}$ was observed for both $\mathrm{MWH}$ and WBH, which is attributed to the improved hydrolysis and olation of the aluminum complexes. At the same temperature, the MWH system always exhibited lower $\mathrm{pH}$ value than the WBH system, and this trend is more and more obvious along with temperature increase. Similarly, compared to the WBH controls, the MWH samples possessed lower conductivities in their effluents, which resulted from the increased absorption of aluminum complexes by hide powder. 
Table 1 Analysis for the tanning effluents of hide powder under different heating methods

\begin{tabular}{|c|c|c|c|c|c|c|c|c|}
\hline & \multicolumn{4}{|c|}{ WBH } & \multicolumn{4}{|c|}{$\mathrm{MWH}$} \\
\hline & $\mathrm{pH}$ & Conductivity (mS/cm) & Dielectric constant & $\mathrm{Al}_{2} \mathrm{O}_{3}(\mathrm{mg} / \mathrm{L})$ & $\mathrm{pH}$ & Conductivity (mS/cm) & Dielectric constant & $\mathrm{Al}_{2} \mathrm{O}_{3}(\mathrm{mg} / \mathrm{L})$ \\
\hline $30^{\circ} \mathrm{C}$ & 4.11 & 35.3 & 1616.77 & 1240.62 & 4.09 & 35.1 & 1622.17 & 1216.44 \\
\hline $40^{\circ} \mathrm{C}$ & 4.08 & 42.3 & 1648.75 & 1221.73 & 4.04 & 40.5 & 1738.75 & 1211.91 \\
\hline $50^{\circ} \mathrm{C}$ & 3.98 & 57.9 & 1657.86 & 895.33 & 3.87 & 57.4 & 2006.79 & 891.56 \\
\hline
\end{tabular}

This point was further confirmed by the results of residual aluminum content in the effluents. Table 1 shows that, at 30,40 and $50^{\circ} \mathrm{C}$, the measured $\mathrm{Al}_{2} \mathrm{O}_{3}$ concentrations are $1216.44,1211.91$ and $891.56 \mathrm{mg} / \mathrm{L}$, respectively, in the MWH effluents, whereas for the WBH effluents, the corresponding values are 1240.62, 1221.73 and $895.33 \mathrm{mg} / \mathrm{L}$. Thus, MWH led to the increased absorption values of $24.18 \mathrm{mg} / \mathrm{L}$ at $30^{\circ} \mathrm{C}, 9.82 \mathrm{mg} / \mathrm{L}$ at $40^{\circ} \mathrm{C}$ and $3.77 \mathrm{mg} / \mathrm{L}$ at $50^{\circ} \mathrm{C}$, respectively. Furthermore, for the dielectric constant of tanning effluent, increased data were observed for the MWH systems at all the tested temperatures. Concretely, the dielectric constants for the MWH effluents are 1622.17 at $30^{\circ} \mathrm{C}, 1738.75$ at $40{ }^{\circ} \mathrm{C}$ and 2006.79 at $50^{\circ} \mathrm{C}$, respectively, whereas in the WBH spent liquors, the corresponding values are 1616.77, 1648.75 and 1657.86 . The increased values by $\mathrm{MWH}$ are 5.4 at $30{ }^{\circ} \mathrm{C}, 90.0$ at $40{ }^{\circ} \mathrm{C}$ and 348.93 at $50{ }^{\circ} \mathrm{C}$, respectively. Dielectric constant is related to the polarity of the tanning system [6]. Heating could lead to the promoted hydrolysis and olation actions of the aluminum tanning agent, which increased the polarity of the tanning liquor. Herein, the dielectric constant is positively related to the temperature change. The higher dielectric constants of MWH is explained by the improved binding ability of aluminum complexes with hide powder and the resulting increased diversity of components in the residual effluents. In short, the above results indicate that temperature increase by both WBH and MWH accelerates hydrolysis and olation of the aluminum complexes, and thus promotes their absorption and combination by hide powder. MWH shows better ability than WBH in this promotion, however. This is because, under microwaves, charged particles and polar ions are forced to oscillate along with the change of electromagnetic field, and the frequency of intermolecular collisions is further increased [6], which is not only beneficial to hydrolysis and olation in the tanning system, but also promotes the participation of carboxyl groups of collagen in the combination with aluminum ions.

\subsubsection{Analysis of tanned hide powder}

Figure 1 shows the $\mathrm{Al}_{2} \mathrm{O}_{3}$ contents of tanned hide powder at different temperatures by both WBH and MWH. Obviously, the aluminum content in tanned hide powder is improved by increasing the tanning temperature, whether through WBH or through MWH. When the temperature was increased from $30^{\circ} \mathrm{C}$ to $40^{\circ} \mathrm{C}$ and then $50^{\circ} \mathrm{C}$, the measured $\mathrm{Al}_{2} \mathrm{O}_{3}$ contents were improved from $47.24 \mathrm{mg} / \mathrm{g}$ to $49.21 \mathrm{mg} / \mathrm{g}$ and then $52.04 \mathrm{mg} / \mathrm{g}$ in the WBH system, whereas in the MWH atmosphere, the corresponding values are 49.62, 51.72 and $54.08 \mathrm{mg} / \mathrm{g}$, respectively. At all the tested temperatures, compared to the conventional WBH, MWH led to higher aluminum contents in the resulting tanned hide powder. This is because microwaves promote the cross-linking process between the aluminum agent with hide collagen [41] and the firmness of the formed cross-linking bonds is better just as microwaves accelerate and promote other chemical reactions.

Thermal stability, which is closely related to the structural stability of tanned products and the configuration of collagen molecules, is reflected by the results of DSC analysis. In the DSC curves, the absorption peak corresponds to the thermal denaturation temperature $\left(\mathrm{T}_{\mathrm{d}}\right)$ of the collagen-based material [42]. Generally, the more the cross-linking bonds locate among the collagen fibers, the greater $\mathrm{T}_{\mathrm{d}}$ of the tanned leather are. As shown in Fig. 2, when the tanning temperature was 30,40 and $50^{\circ} \mathrm{C}$, respectively, the corresponding $\mathrm{T}_{\mathrm{d}}$ values of tanned hide powder treated in the WBH system were 67,81 and $81^{\circ} \mathrm{C}$; for the samples in the MWH system, the $T_{d}$ results improved to 77,83 and $84^{\circ} \mathrm{C}$, respectively. At the same temperature, $\mathrm{MWH}$ leads to higher $\mathrm{T}_{\mathrm{d}}$ than $\mathrm{WBH}$, which indicates that microwave irradiation possesses the

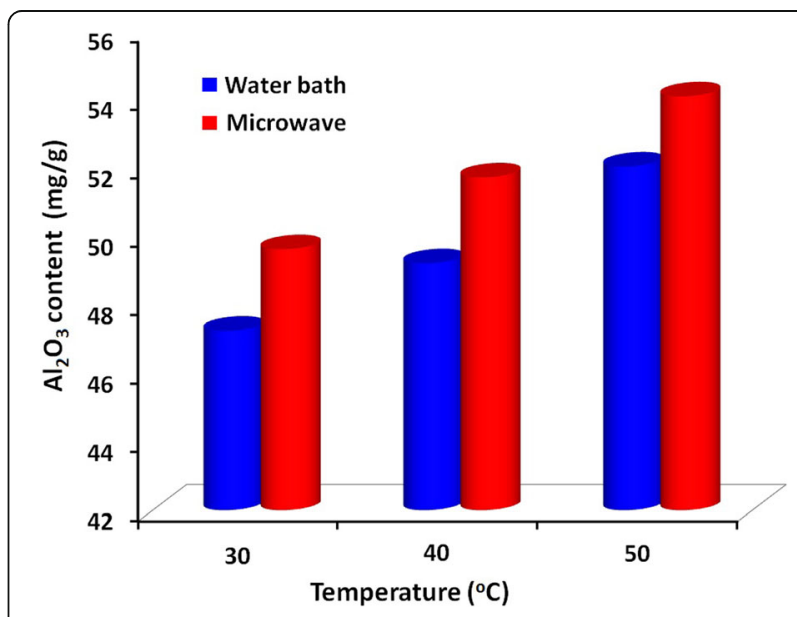

Fig. 1 Aluminum contents of hide powder tanned at $30^{\circ} \mathrm{C}, 40^{\circ} \mathrm{C}$ and $50^{\circ} \mathrm{C}$ under different heating methods 

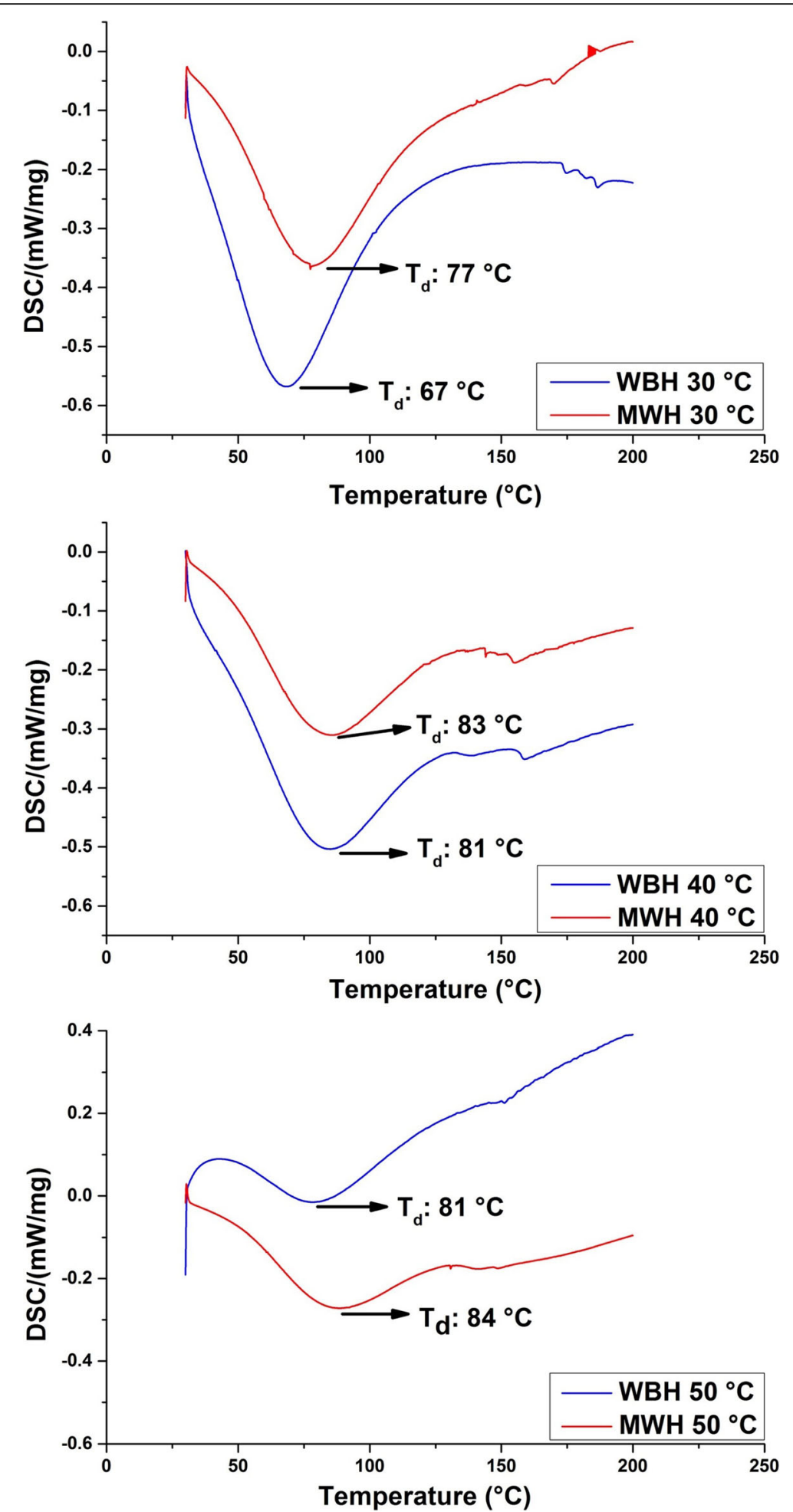

Fig. 2 DSC curves of hide powder tanned at $30^{\circ} \mathrm{C}, 40^{\circ} \mathrm{C}$ and $50^{\circ} \mathrm{C}$ under different heating methods

improved ability to promote and further fix the formation of cross-linking bonds between the collagen fibers and aluminum complexes. Thus, the resulting hide powder presents a better thermal stability. When the aluminum tanning was conducted at $30^{\circ} \mathrm{C}$, a relatively low temperature, the $\mathrm{T}_{\mathrm{d}}$ of $\mathrm{MWH}$ sample $\left(77^{\circ} \mathrm{C}\right)$ was greatly higher than that of the WBH control $\left(67^{\circ} \mathrm{C}\right)$. The difference between the two samples was about $10^{\circ} \mathrm{C}$. 
This great difference is resulted from the athermal effect of microwave irradiation, which is more prominent at lower temperature. When the tanning temperature was improved to 40 or $50^{\circ} \mathrm{C}$, this difference was only about $3{ }^{\circ} \mathrm{C}$, which is explained by the dominance of thermal effect of microwave at higher temperatures.

The TG technique was further adopted to characterize the thermal stability of tanned hide powder. Table 2 shows the maximum thermal decomposition temperature $\left(\mathrm{T}_{\max }\right)$ of the tanned hide powder and the mass-loss ratios at three stages. The corresponding TG and DTG curves are provided in Figs. S1, S2, S3, S4, S5 and S6 in the supplementary information (SI). Like the cases of other collagen-based materials, all the TG curves of tanned hide powder possess three massloss stages during the heating range from 50 to $700^{\circ} \mathrm{C}$. The first mass-loss mainly occurred at $40-120^{\circ} \mathrm{C}$, and the corresponding mass-loss ratios were about $13 \%$. This thermal mass-loss is mainly attributed to the removal of $\mathrm{H}_{2} \mathrm{O}$ and other volatile substances with small molecular weight in hider powder [41]. Especially, for each TG curve, the weightloss in the first stage was deduced to calculate the weightloss data in the second and third stages, which is beneficial to study the thermal stability of tanned hide powder without the impact of water.

The biggest mass-loss process of all the TG curves is the second stage, as a result of collagen decomposition during the pyrolysis process [41]. According to Table 2, the second mass-loss ratios of aluminum tanned hide powder were also moderately different at different tanning temperatures. For example, for the tanning at $30{ }^{\circ} \mathrm{C}$, the mass-loss ratios are $41.1 \%$ for $\mathrm{MWH}$ and $41.9 \%$ for $\mathrm{WBH}$, respectively. When the temperature was increased to $40^{\circ} \mathrm{C}$, the mass-loss ratios decreased to
$40.3 \%$ for $\mathrm{MWH}$ and $41.3 \%$ for $\mathrm{WBH}$. When the temperature was further improved to $50^{\circ} \mathrm{C}$, the massloss ratios are reduced to $37.6 \%$ for $\mathrm{MWH}$ and $38.9 \%$ for WBH, respectively. These results indicate that, along with the increase of tanning temperature, mass-loss ratio in the second stage reduced gradually. The reason is that the cross-linking degree in hide powder gradually increased. The thermal decomposition resistance was thus enhanced, as well as the conformation stability of the aluminum tanned hide powder. The second mass-loss ratios for $\mathrm{MWH}$ samples were always lower than those of WBH controls at the same tanning temperature, which reveals that MWH leads to an increased thermal stability of the aluminum tanned hide powder.

$\mathrm{T}_{\max }$ in the second stage is affected by the crosslinking degree and strength between tanning agent and collagen [42]. The higher the cross-linking strength and degree are, the higher $\mathrm{T}_{\max }$ becomes, which means the better thermal stability of the aluminum tanned hide powder. Specifically, when the aluminum tanning of hide powder was carried out at $30^{\circ} \mathrm{C}, \mathrm{T}_{\max }$ of $\mathrm{WBH}$ was $301{ }^{\circ} \mathrm{C}$, whereas $\mathrm{T}_{\max }$ of $\mathrm{MWH}$ was $305^{\circ} \mathrm{C}$. The former was about $4{ }^{\circ} \mathrm{C}$ lower than the latter. When the tanning temperature was improved to $40^{\circ} \mathrm{C}$, the $\mathrm{T}_{\max }$ values improved to $306^{\circ} \mathrm{C}$ for $\mathrm{WBH}$ and $307^{\circ} \mathrm{C}$ for $\mathrm{MWH}$, and the difference value between them was $1{ }^{\circ} \mathrm{C}$ or so. When the tanning was performed at $50^{\circ} \mathrm{C}$, the $\mathrm{T}_{\max }$ data were further increased to $308^{\circ} \mathrm{C}$ for $\mathrm{WBH}$ and $309^{\circ} \mathrm{C}$ for $\mathrm{MWH}$, and the difference between the two groups was about $1{ }^{\circ} \mathrm{C}$. As expected, the $\mathrm{T}_{\max }$ values of MWH samples are always higher than those of WBH controls, which indicates that microwave irradiation exhibits greater promotion for the cross-linking interaction

Table 2 TG analysis of tanned hide powder obtained under different heating methods

\begin{tabular}{|c|c|c|c|c|c|}
\hline Sample & $\begin{array}{l}T_{\max } \\
\left({ }^{\circ} \mathrm{C}\right)\end{array}$ & $\begin{array}{l}\text { Mass-loss ratio of the first stage } \\
(\%)\end{array}$ & $\begin{array}{l}\text { Mass-loss ratio of the second stage } \\
(\%)\end{array}$ & $\begin{array}{l}\text { Mass-loss ratio of the third stage } \\
(\%)\end{array}$ & $\begin{array}{l}\text { Residue ratio } \\
\text { (\%) }\end{array}$ \\
\hline \multicolumn{6}{|c|}{$30^{\circ} \mathrm{C}$} \\
\hline WBH & 301 & 12.4 & $36.7 / 41.9^{a}$ & $3.20 / 3.7^{a}$ & $47.72 / 54.5^{a}$ \\
\hline \multicolumn{6}{|c|}{$\mathrm{MWH}$} \\
\hline & & & $40^{\circ} \mathrm{C}$ & & \\
\hline WBH & 306 & 13.6 & $35.7 / 41.3^{a}$ & $2.25 / 2.6^{a}$ & $48.52 / 56.1^{a}$ \\
\hline \multicolumn{6}{|c|}{$\mathrm{MWH}$} \\
\hline \multicolumn{6}{|c|}{$50^{\circ} \mathrm{C}$} \\
\hline WBH & 308 & 13.4 & $33.7 / 38.9^{\mathrm{a}}$ & $3.34 / 3.9^{a}$ & $49.54 / 57.2^{a}$ \\
\hline $\mathrm{MWH}$ & 309 & 13.0 & $32.7 / 37.6^{\mathrm{a}}$ & $3.20 / 3.7^{\mathrm{a}}$ & $51.08 / 58.7^{a}$ \\
\hline
\end{tabular}

${ }^{\mathrm{a}}$ The value calculated when the moisture content is deducted 
between aluminum complexes and collagen fibers, and the tanned products thus have better thermal decomposition resistance. In addition, when the tanning temperature was performed at a lower temperature of $30^{\circ} \mathrm{C}$, the $\mathrm{T}_{\max }$ difference between $\mathrm{MWH}$ and $\mathrm{WBH}$ was the largest. This shows that the non-thermal effect of microwave is more prominent at lower temperature, corresponding to the results of DSC.

As can be seen from Table 2, a slight weight-loss took place in the third stage, resulting from further decomposition of organic molecules in hide powders. There is no great difference among WBH and MWH samples, although the former normally exhibit slightly larger values than the latter. The residue ratios were $54.5 \%$ of $30{ }^{\circ} \mathrm{C}$, $56.1 \%$ of $40^{\circ} \mathrm{C}$ and $57.2 \%$ of $50^{\circ} \mathrm{C}$, respectively, for the WBH controls, whereas for the MWH samples the corresponding ratios were $55.4 \%, 55.9 \%$ and $58.7 \%$, respectively. The residue is composed of the carbonization products of aluminum tanned hide powder. Normally, the MHW samples show higher residue ratios than WBH controls under the same conditions, which is attributed to the firmer combination of aluminum tanning agent with hide fibers due to the thermal and athermal effect of the microwaves [38].

The IR spectra of aluminum tanned hide powder with different heating methods are shown in Fig. S7 of the SI. No large difference was observed by comparing the IR spectra of WBH and MWH samples, and the major characteristic peaks of collagen are assigned as follows. The peak at $3414 \mathrm{~cm}^{-1}$ corresponds to the amide A band that is resulted from the $\mathrm{N}-\mathrm{H}$ stretching vibration of the amide groups of collagen macromolecules. The weak absorption peak at $2969 \mathrm{~cm}^{-1}$ arises from the amide B band that is related to the $\mathrm{C}-\mathrm{N}$ stretching vibration. The amide I band, caused by the $\mathrm{C}=\mathrm{O}$ stretching vibration, is located at $1658 \mathrm{~cm}^{-1}$. The absorption peak at 1550 $\mathrm{cm}^{-1}$ is assigned to the amide II band that reflects the $\mathrm{N}-\mathrm{H}$ stretching vibration intensively coupled to the $\mathrm{C}-\mathrm{N}$ stretching vibration. The amide III band from the $\mathrm{N}-\mathrm{H}$ bending vibration is located at 1369 $\mathrm{cm}^{-1}$ [43]. The fact that these characteristic bands have no significant change shows that neither MWH nor WBH could lead to the change of collagen structure in hide powder. Even so, the amide A band for the MWH samples was significantly wider than that of the WBH controls. The reason might be that there are association interactions between the $\mathrm{N}-\mathrm{H}$ and hydrogen bonds leading to the increased number of hydrogen bonds among collagen molecular chains, and further resulting in the decrease in the bond force constant of the $\mathrm{N}-\mathrm{H}$ bonds and their stretching vibration frequency [44]. This means that, under microwave, there were more functional groups in collagen molecules of hide powder participating in coordination and binding with aluminum ions.

\subsection{Effect of microwave irradiation on the aluminum tanning of skin pieces \\ 3.2.1 $\mathrm{pH}$ change during tanning process}

The penetration of tanning molecules into hide interior and their binding to collagen fibers are two main processes during aluminum tanning process. Generally, aluminum complexes are supposed to penetrate into hide collagen fibers quickly and uniformly in the early stage of tanning. At a later period of tanning, the environmental $\mathrm{pH}$ improved upon basification, and the tanning molecules become larger due to hydrolysis $\left(\left[\mathrm{Al}\left(\mathrm{H}_{2} \mathrm{O}\right)_{6}\right]^{3+} \rightarrow\left[\mathrm{Al}(\mathrm{OH})\left(\mathrm{H}_{2} \mathrm{O}\right)_{5}\right]^{2+}+\mathrm{H}^{+}\right)$and olation reactions of $\mathrm{Al}(\mathrm{III})$ ions. At the same time, the side-chain active groups (e.g. - $\mathrm{COOH}$ ) of collagen fibers access the inner boundary of aluminum complexes and coordinate with the central $\mathrm{Al}(\mathrm{III})$ ion [1]. To further simulate the aluminum tanning process, skin pieces with small size were adopted and tanned under MWH and WBH conditions, respectively. Similarly, the tanning liquors and the tanned leather pieces were analyzed and compared to reveal the effect of microwave irradiation.

Figure 3 provides the $\mathrm{pH}$ change of the tanning solution with different heating methods. Whether in the MWH system or in the WBH control, it was clear that $\mathrm{pH}$ has decreased gradually during the first $5 \mathrm{~h}$ (Fig. 3a). The basification was carried out during the subsequent $5 \mathrm{~h}$ by adding some $\mathrm{NaHCO}_{3}$ every hour, and during this period, the $\mathrm{pH}$ of the tanning solution gradually improved to finally reach about 3.8 (Fig. $3 \mathrm{~b}$ ). According to previous works [12] and experimental results of hide powder in the present study, microwave facilitated both the hydrolysis and olation actions in the aluminum tanning process. Thus as anticipated, the $\mathrm{pH}$ values of the tanning solution under microwave were always lower than the ones of water bath during the whole tanning period. The reason is relevant to the promotion effect of the microwaves, and also to the higher dielectric constant of the MWH system [12]. The solvent with a high dielectric constant absorbs microwave energy at a significantly increased rate [9]. This increases the probability of collisions among tanning molecules, and in turn accelerates the dissociation rate of side-chain carboxyl groups of collagen fibers and further facilitates their binding with aluminum complexes.

\subsection{2 $\mathrm{Al}_{2} \mathrm{O}_{3}$ content and $T_{s}$}

Table 3 provides the $T_{s}$ results of tanned skin pieces, $\mathrm{Al}_{2} \mathrm{O}_{3}$ contents in tanning effluents and tanned skin pieces under both heating methods. Compared to the case of WBH control, the $\mathrm{Al}_{2} \mathrm{O}_{3}$ content of tanning effluent in the MWH system was significantly reduced 

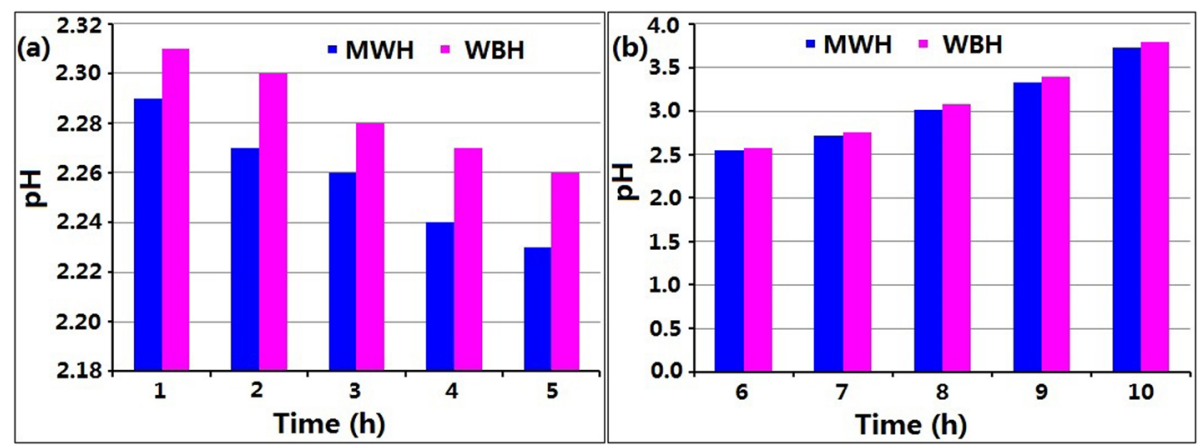

Fig. 3 The pH change of aluminum tanning solutions before (a) and after (b) basification treatment

from $1240.64 \mathrm{mg} / \mathrm{L}$ to $895.33 \mathrm{mg} / \mathrm{L}$. Accordingly, the MWH tanned skin piece has significantly higher $\mathrm{Al}_{2} \mathrm{O}_{3}$ content than the WBH control. The determined values are $38.21 \mathrm{mg} / \mathrm{g}$ for the former and $35.74 \mathrm{mg} / \mathrm{g}$ for the latter. Thus, these data reveal that the microwaves promote the exhaustion of aluminum tanning agent by skin pieces, thereby significantly reduce the aluminum content in the residual effluent. This is of great benefit for the clean production of aluminum tanning. In addition, Table 3 shows that the $T_{s}$ of tanned skin pieces under microwave is $74.0^{\circ} \mathrm{C}$, whereas the control provides $T_{s}$ of only $72.9^{\circ} \mathrm{C}$. Namely, microwave irradiation leads to the increase of $\mathrm{T}_{\mathrm{s}}$ by $1.1^{\circ} \mathrm{C}$. This is due to microwave increase of the absorption rate of the aluminum tanning agent during the tanning process; it promotes and further fixes the cross-linking between aluminum tanning complexes and collagen fibers.

\subsubsection{Thermal analysis}

Similarly, DSC and TG measurements were carried out to study the action of microwave irradiation on the thermal stability of aluminum-tanned leather pieces. Figure 4 shows that the $\mathrm{T}_{\mathrm{d}}$ of tanned skin piece heated by

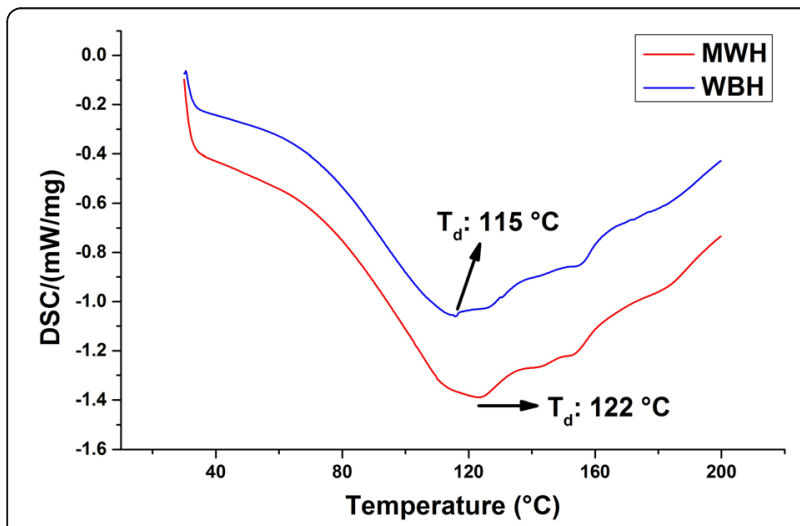

Fig. 4 DSC curves of aluminum tanned skin pieces under different heating methods microwave is $122^{\circ} \mathrm{C}$, whereas the $\mathrm{T}_{\mathrm{d}}$ of the control prepared in water bath is only $115^{\circ} \mathrm{C}$. The former is $7{ }^{\circ} \mathrm{C}$ higher than the latter, which further proves the promotion of microwaves on aluminum tanning. Namely, microwave irradiation leads to increased cross-linking combination between collagen fibers and aluminum complexes, and the firmness of cross-linking bonds is improved, too [38]. Thus, the higher thermal stability of the tanned product is observed in the microwave heating system.

Figure 5 shows the TG/DTG curves of aluminum tanned skin pieces with different heating methods. Similar to the case of skin powder (Table 2), the TG curve also presents three distinct weight-loss stages. The first weight-loss mainly occurs at $50-120^{\circ} \mathrm{C}$, too, and the corresponding mass-loss ratios are $21.8 \%$ for the MWH sample and $19.1 \%$ for the WBH control, respectively. This mainly results from the removal of $\mathrm{H}_{2} \mathrm{O}$ and other volatile small-size substances in tanned skin pieces [45]. The obvious weight-loss process on the TG curves is the second stage from 200 to $500{ }^{\circ} \mathrm{C}$, which mainly resulted from the break of cross-linking bonds between collagen fibers [41]. When the content of $\mathrm{H}_{2} \mathrm{O}$ is deducted, the revised weight-loss ratios for the second stage are $45.4 \%$ for the MWH sample and $46.6 \%$ for the WBH control, respectively. As expected, the microwave irradiation results in a deceased value, which is due to the more stable network of tanned skin formed by the increased crosslinking bonds. In addition, the $\mathrm{T}_{\max }$ values are $317^{\circ} \mathrm{C}$ for the tanned skin piece heated water bath and $321^{\circ} \mathrm{C}$ for the MWH sample, respectively. Compared to the WBH, $\mathrm{MWH}$ leads to the increase of $\mathrm{T}_{\max }$ by $4{ }^{\circ} \mathrm{C}$. These data also confirm that under microwaves, the degree of cross-

Table $3 \mathrm{~T}_{\mathrm{s}}$ and $\mathrm{Al}_{2} \mathrm{O}_{3}$ contents in tanning effluent and tanned skin pieces

\begin{tabular}{llll}
\hline Sample & Tanning effluent $(\mathrm{mg} / \mathrm{L})$ & leather pieces $(\mathrm{mg} / \mathrm{g})$ & $\mathrm{T}_{\mathrm{s}}\left({ }^{\circ} \mathrm{C}\right)$ \\
\hline WBH & 1240.62 & 35.74 & 72.9 \\
$\mathrm{MWH}$ & 895.33 & 38.21 & 74.0 \\
\hline
\end{tabular}



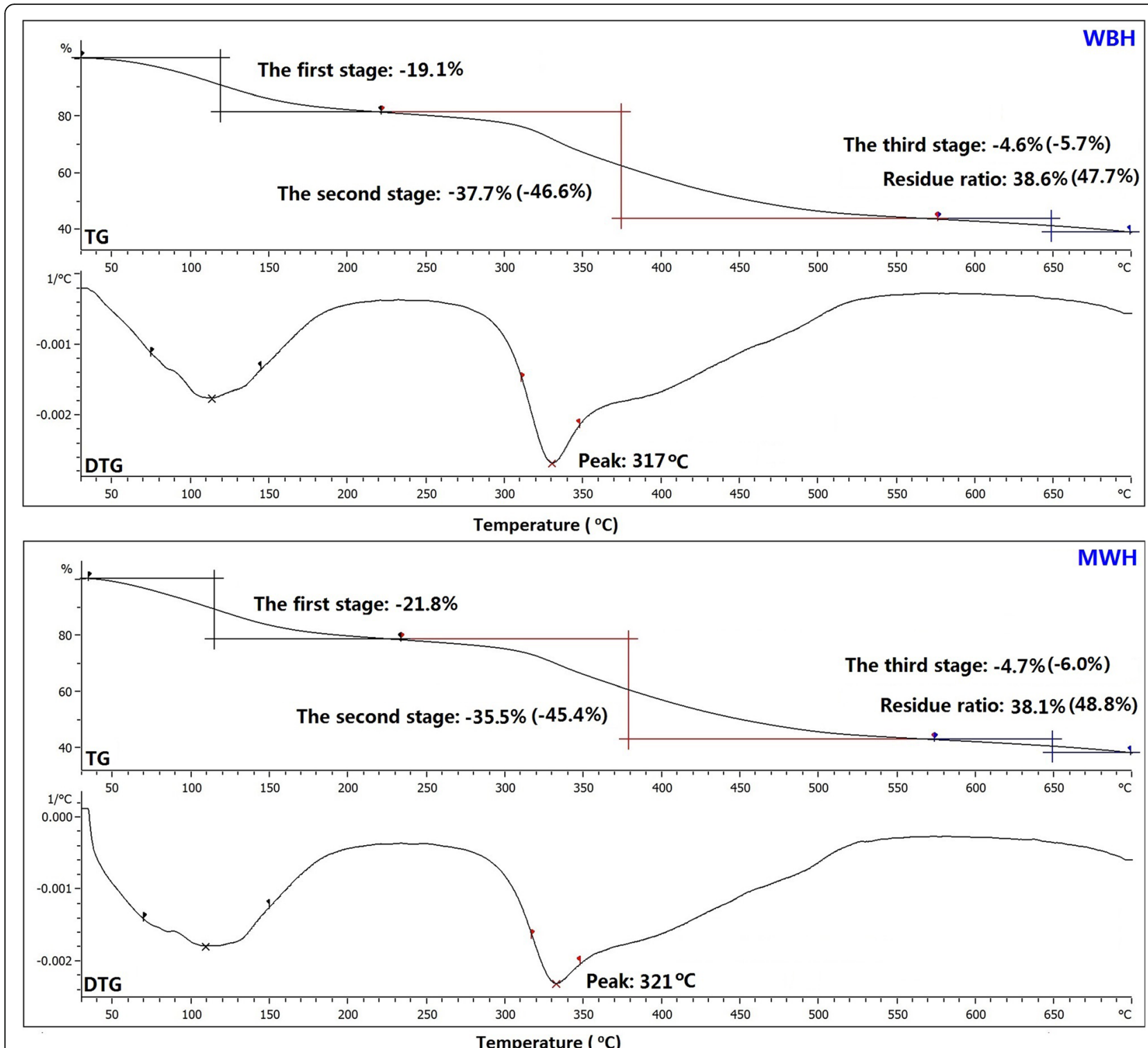

Fig. 5 TG/DTG curves of aluminum tanned skin pieces under different heating methods

linking between aluminum tanning agent and collagen fibers improves, and the conformational stability of tanned skin pieces is enhanced. This results in an improved thermal decomposition resistance. The third weight-loss stages were also observed for both samples. Like the case of tanned hide powder (Table 2), the tanned skin pieces exhibit slight weight-loss in this stage; no large difference was found for both WBH and MWH samples. The final residue ratios were calculated to be $47.7 \%$ for the WBH control and $48.8 \%$ for the MWH sample. The increased value for the latter is also a proof for the better thermal stability of tanned skin piece heated by microwaves.

Furthermore, the FT-IR technique was also used to provide the information about the characteristic functional groups of collagen in tanned skin pieces. These spectra are shown in Fig. 6. The characteristic amide A (3438 $\left.\mathrm{cm}^{-1}\right), \mathrm{B}\left(2974 \mathrm{~cm}^{-1}\right)$, I $\left(1726 \mathrm{~cm}^{-1}\right)$, II $\left(1586 \mathrm{~cm}^{-1}\right)$ and III $\left(1369 \mathrm{~cm}^{-1}\right)$ bands are observed in both IR spectra of $\mathrm{WBH}$ and $\mathrm{MWH}$ samples, and no large difference is found in the position and shape of these peaks, indicating that microwave and water bath do not change the collagen structure of the aluminum tanned skin pieces.

\subsubsection{SEM-EDX analysis}

To further explore the action of microwave on the hierarchical structure of aluminum-tanned skin pieces, SEM-EDX analysis was carried out, and the results are illustrated in Figs. 7 and 8. Figure 7 provides the SEM images of aluminum tanned skin pieces with different 


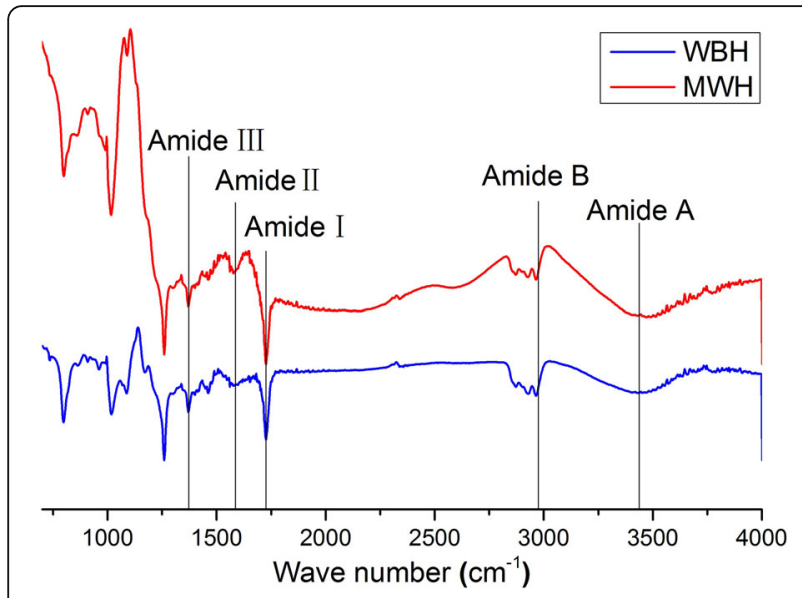

Fig. 6 FT-IR spectra of aluminum tanned skin pieces under different heating methods

heating methods, and the magnifications are 50, 5000, and 50,000, respectively. At the magnification of 50, there is no significant difference on the microstructure between the $\mathrm{MWH}$ and $\mathrm{WBH}$ samples. When the magnification is improved to 5000, the fiber bundle width of the WBH control is $3 \pm 1 \mu \mathrm{m}$, whereas the width for the MWH sample is increased to $4 \pm 1 \mu \mathrm{m}$, and it's obvious that the collagen fibers under microwave irradiation are tighter. The reason may be that the penetration process of aluminum ions is promoted by microwave irradiation, and thus there are more cross-linking bonds formed in the network of fiber bundles to make the width increase. In addition, crystal-like particles were found absorbed among or on the fiber bundles, and these particles should be composed of aluminum complexes and other salts. When the magnification is further improved to 50,000, the unique collagen $1 / 4$ staggered structure is shown by the hollow area and the overlapping area [26] in both samples. These results indicate that both $\mathrm{MWH}$ and WBH cannot damage the 1/ 4 staggered structure of collagen fibers.

The distribution of aluminum elements on the crosssections of tanned skin pieces was also studied by the coupled EDX analysis of SEM measurement, and the corresponding EDX spectra are shown in Fig. 8 and the original SEM images used could be found in Figs. S8 and S9 in the SI. The red signals correspond to the presence of aluminum elements, and their density and distribution are attributed to the content and penetration of aluminum tanning agent on the cross-section of tanned leather. Compared with the WBH control, the signals of the MWH sample are much brighter, and more uniformly distributed in the crosssection of tanned skin pieces. The brighter signals indicate the higher content of aluminum element, which is in line with the above result of $\mathrm{Al}_{2} \mathrm{O}_{3}$ analysis (Table 3). More importantly, the EDX results confirm the evener distribution of aluminum tanning agent in the cross-section of tanned leather heated by microwave irradiation. This reveals that microwave irradiation not only retains the collagen structure of skin pieces, but also promotes the penetration of the aluminum tanning agent in skin pieces, which is favorable to the improvement of the overall properties of the obtained leather.

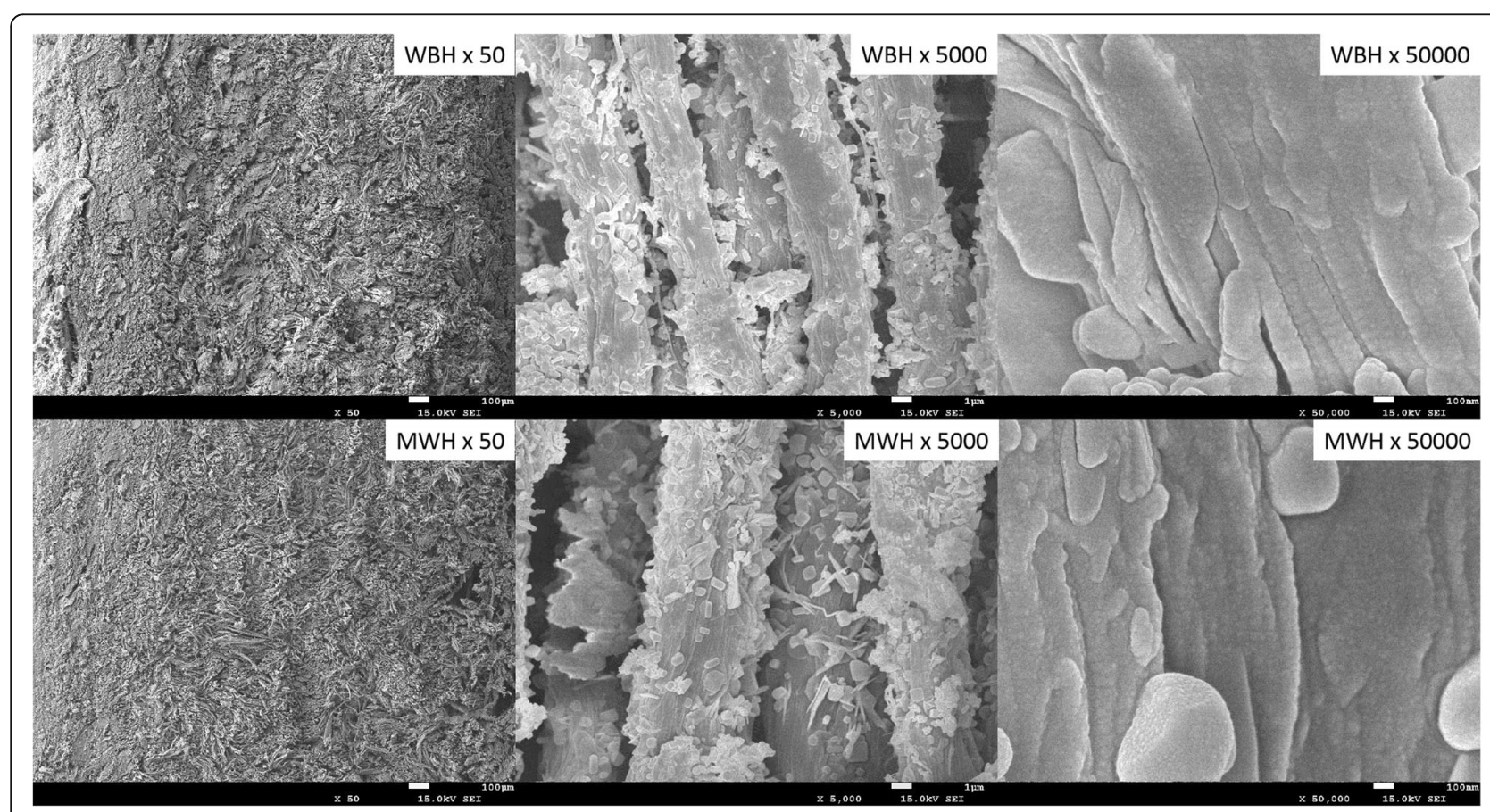

Fig. 7 SEM images of aluminum tanned skin pieces under different heating methods 

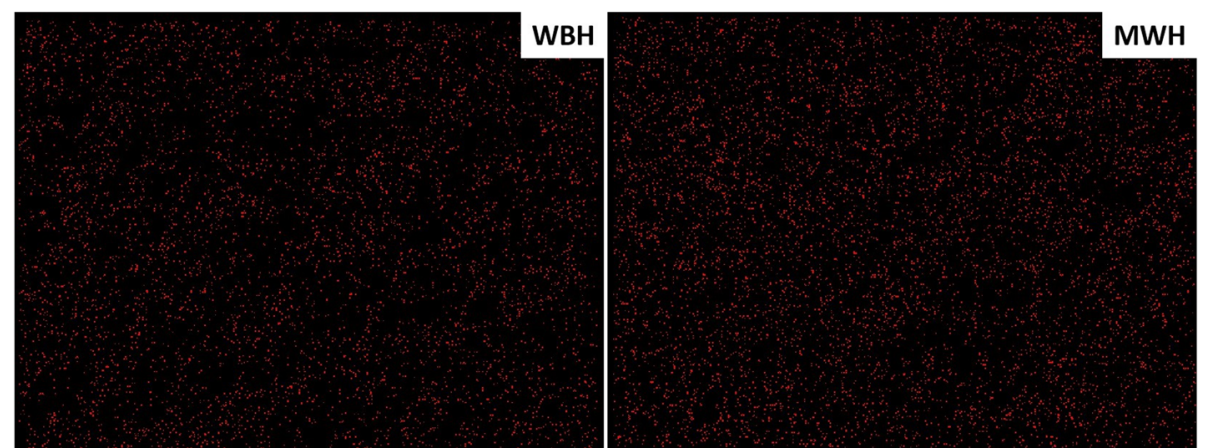

Fig. 8 The aluminum distribution in tanned skin pieces by EDX under different heating methods

XPS measurement is also performed to analyze the action of microwaves on the structure of tanned skin pieces. Figure 9 is the full spectra of XPS including C, O, $\mathrm{N}$ and $\mathrm{Al}$ elements in a specific orbital binding energy. Figs. S10, S11 and S12 in the SI are the corresponding enlarged spectra of $\mathrm{Al}, \mathrm{C}$ and $\mathrm{O}$ elements. As can be seen from the above XPS spectra, the binding energy of $\mathrm{C}, \mathrm{O}, \mathrm{N}$ and $\mathrm{Al}$ in aluminum tanned skin pieces obtained by WBH and MWH did not change significantly. Furthermore, the different peaks at $500 \mathrm{eV}$ and $1100 \mathrm{eV}$ are corresponding to the Na KLL, Na $1 \mathrm{~s}$, respectively. The $\mathrm{Na}$ element was resulted from the pickling solution containing $\mathrm{NaCl}$ used to prevent the acid-swelling of skin

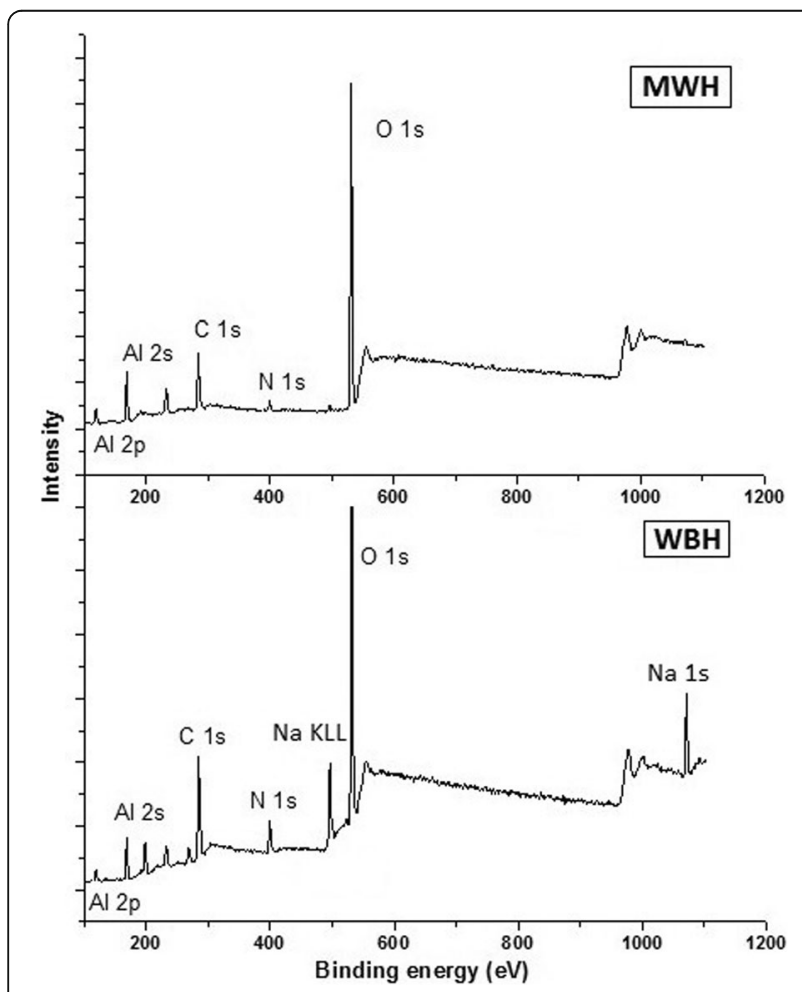

Fig. 9 XPS spectra of aluminum tanned skin pieces under different heating methods pieces. The XPS results indicate that both WBH and MWB neither change the combination mode of the aluminum tanning agent molecules with collagen fibers in the skin pieces, nor damage the structure of the collagen fibers. Furthermore, the relative signal intensities of $\mathrm{Al}$ to $\mathrm{C}, \mathrm{N}$ and $\mathrm{O}$ elements, respectively, in the $\mathrm{MWH}$ sample is stronger than those in the WBH control, which is explained by the higher $\mathrm{Al}$ content in the tanned skin piece heated by microwaves.

\section{Conclusions}

In summary, the heterogeneous aluminum tanning of hide powder and skin pieces has been investigated under microwave irradiation. The conventional water bath heating was adopted as the control to study the action of microwave heating on the aluminum-tanning process, and the structure and property of the corresponding tanned products. Both thermal and athermal effects of microwaves were found to be beneficial to the aluminum tanning, and the following main conclusions could be drawn:

(1) Microwave heating promoted the absorption, penetration and bonding process of the aluminum tanning agent, significantly reducing the aluminum content in waste liquid, which is favorable for clean tanning and improvement of the aluminum content in tanned leather.

(2) Microwave heating presents better thermal stability and thermal decomposition resistance for hide powder and skin pieces.

(3) The structure of tanned hide powder and skin pieces is not damaged under microwaves.

(4) This study is of interest for the theoretical guidance and practical reference concerning application of microwaves in aluminum-based tanning. And future work will focused on the development of specialized microwave-heating tanning device (e.g. drum) and the cost estimation, which is beneficial for the large-scale application of this procedure. 


\section{Supplementary information}

Supplementary information accompanies this paper at https://doi.org/10. 1186/s42825-020-00037-w

Additional file 1: Fig. S1. TG/DTG curves of tanned hide powder with WBH at $30^{\circ} \mathrm{C}$. Fig. S2. TG/DTG curves of tanned hide powder with MWH at $30^{\circ} \mathrm{C}$. Fig. S3. TG/DTG curves of tanned hide powder with WBH at $40^{\circ} \mathrm{C}$. Fig. S4. TG/DTG curves of tanned hide powder with $\mathrm{MWH}$ at $40^{\circ} \mathrm{C}$. Fig. S5. TG/DTG curves of tanned hide powder with $\mathrm{WBH}$ at $50^{\circ} \mathrm{C}$. Fig. S6. TG/DTG curves of tanned hide powder with $\mathrm{MWH}$ at $50^{\circ} \mathrm{C}$. Fig. S7. FT-IR spectra of aluminum tanned hide powder at $30^{\circ} \mathrm{C}, 40^{\circ} \mathrm{C}$ and $50^{\circ} \mathrm{C}$ with different heating methods. Fig. S8. SEM image for EDX analysis for the cross-section of aluminum tanned skin pieces of $\mathrm{WBH}$. Fig.

S9. SEM image for EDX analysis for the cross-section of aluminum tanned skin pieces of MWH. Fig. S10. XPS-Al images of tanned skin pieces with different heating methods. Fig. S11. XPS-C images of tanned skin pieces with different heating methods. Fig. S12. XPS-O images of tanned skin pieces with different heating methods.

\section{Abbreviations}

DSC: Differential scanning calorimetry; EDX: Energy dispersive X-ray spectroscopy; FT-IR: Fourier transform infrared spectroscopy; ICP-AES: Inductively coupled plasma atomic emission spectrometry; MWH: Microwave heating; SEM: Scanning electron microscope; SI: Supplementary information; $T_{d}$ : Increased thermal denaturation temperature; $T_{\text {max }}$ : Maximum thermal decomposition temperature; $T_{s}$ : Shrinkage temperature; TG: Thermogravimetric; WBH: Water bath heating; XPS: X-ray photoelectron spectroscopy

\section{Acknowledgements}

The authors thank Zhonghui Wang (College of Biomass Science and Engineering, Sichuan University) for her help in the DSC analysis.

\section{Authors' contributions}

Yue Liu performed all the experiments and was a major contributor in data analyses and writing of this manuscript. Bin Song took part in the experiments about hide powder. Jinwei Zhang and Carmen Gaidau made substantial contributions to the design and implement of the experiments in this work. Haibin Gu is the superior of this work and made great contribution to the conception of the study, the discussion of the results and the revision of the manuscript. All authors have read and approved the final manuscript.

\section{Authors' information}

Not applicable.

\section{Funding}

Financial support from the National Natural Science Foundation (No. 21576171) and the Science \& Technology Department of Sichuan Province (No. 2018H H0038) is gratefully acknowledged. The author of Bin Song was funded by the Innovation Training Program for college students of Sichuan University (C2020107809).

\section{Availability of data and materials}

All data needed to evaluate the conclusions in the paper are present in the paper and the supplementary material.

\section{Competing interests}

The authors declare that they have no competing interest.

\section{Author details}

${ }^{1}$ Key Laboratory of Leather Chemistry and Engineering of Ministry of Education, Sichuan University, Chengdu 610065, China. ${ }^{2}$ National Engineering Research Center of Clean Technology in Leather Industry, Sichuan University, Chengdu 610065, China. ${ }^{3}$ Leather Research Department, The Research and Development National Institute for Textiles and Leather-Division Leather and Footwear Research Institute, 93, Ion Minulescu Str, Bucharest, 3, Romania.
Received: 1 May 2020 Accepted: 16 August 2020

Published online: 25 August 2020

\section{References}

1. Chen WY, Li GY. Tanning chemistry. 4th ed. Beijing: China Light Industry Press; 2018.

2. Huang KM, Liu YQ, Tang JX, Lan X. Microwave chemistry-an emerging cross science. Electron Technol Guide. 1994;1:20-1.

3. Zhu YJ, Chen F. Microwave-assisted preparation of inorganic nanostructures in liquid phase. Chem Rev. 2014;114:6462-555

4. He WZ, Guo XY. Microwave chemistry in polymer organic synthesis. Sci Technol Inform. 2009;9:87-8.

5. Ji R, Liu ZJ, Liu SS, Wang PJ, Wang ZK. Application of microwave chemistry in polymer organic synthesis. Chem Int. 2018;17(2):20-1.

6. Jin QH, Dai SS, Huang KM. Microwave chemistry. Beijing: Science Press; 1999.

7. Lu MW, Hu WX. Progress in organic microwave chemistry. Org Chem. 1995; 15(6):561-6

8. Gawande MB, Shelke SN, Zboril R, Varma RS. Microwave-assisted chemistry: synthetic applications for rapid assembly of nanomaterials and organics. Acc Chem Res. 2014;47:1338-48.

9. Wang P, Zheng T, Zhang GS. Environmental microwave chemistry. Beijing: Science Press; 2014

10. Xia ZX, Liu CJ, Yan LP, Yang XQ. Progress in the application of microwave chemistry. Chem Res Appl. 2004;16(4):441-4.

11. Leonelli C, Mason TJ. Microwave and ultrasonic processing: now a realistic option for industry. Chem Eng Process. 2010;49(9):885-900.

12. Cao N, Zhang JW, Wang SJ, Chen WY. Behaviors of chromium nitrate hydrolysis and olation under microwave irradiation. Leather Sci Eng. 2016; 26(4):5-9.

13. Chen J, Li XZ, Wang ZW, Chen RL, Chen WY. Microwave irradiation assisted the stability constant of chromium(III) complexes. Leather Sci Eng. 2019; 29(2):24-9.

14. Chen J, Zhang JW, Zhou N, Chen WY. Influence of microwave irradiation on the stability of chromium(III) complexes. Leather Sci Eng. 2017;27(04):5-9.

15. Wang $H$, Chen WY, Gong Y, Sun HB. Based on the studies of chrome tanning chemistry with microwave. Leather Sci Eng. 2011;21(2):5-9.

16. Zhang JW, Cao N, Zhou N, Chen WY. Hydrolysis and olation of chromium sulphate under microwave irradiation. J Soc Leather Technol Chem. 2017; 101(1):1-5.

17. Costa ACS, Assis JCR, Torres ALC, Ferreira SLC, Korn MD, Teixeira LSG. Spectrophotometric determination of chromium with EDTA using microwave oven. Quim Nova. 1999:22(2):194-6.

18. Wu JC, Fan ZW, Zhang JW, Chen WY. Impact of microwave irradiation on vegetable tanning. J Soc Leather Technol Chem. 2018;102(1):7-11.

19. Wu JC, Zhang L, Zhang JW, Chen WY. Electrochemical behavior of tannin solutions under microwave irradiation. Leather Footwear J. 2017;17(2):91-6.

20. Fang $Y T$, Zhang JW, Ning GQ, Chen WY. Effects of microwave irradiation on hydrolysis of zirconium sulfate and thermal stability of zirconium tanned powder. Leather Sci Eng. 2017;27(3):12-6.

21. Ning GQ, Wu JC, Zhang JW, Fang YT, Chen WY. Effect of microwave irradiation on the hydrolysis and olation of titanium solution. Leather Sci Eng. 2018;28(05):12-5.

22. Ruijgrok JM, Boon ME, Feirabend HKP, Ploeger S. Does microwave irradiation have other than thermal effects on glutaraldehyde cross-linking of collagen. Eur J Morphol. 1993;31(4):290-7.

23. Ruijgrok JM, Dewijn JR, Boon ME. A model to determine microwavestimulated cross-linking of collagen using diluted glutaraldehyde solutions. Scanning. 1993;15(2):110-4.

24. Ruijgrok JM, Dewijn JR, Boon ME. Optimizing glutaraldehyde cross-linking of collagen-effects of time, temperature and concentration as measured by shrinkage temperature. J Mater Sci Mater Med. 1994;5(2):80-7.

25. Visser CE, Voute ABE, Oosting J, Boon ME, Kok LP. Microwave irradiation and cross-linking of collagen. Biomaterials. 1992;13(1):34-7.

26. LV XY, Lu X. Lecture on the history of Chinese tanning technology. West Leather. 2000;2:46-7.

27. Covington AD. The 1998 John Arthur Wilson memorial lecture: new tannages for the new millennium. J Am Leather Chem Assoc. 1998;93(6):168-82.

28. Covington AD. Quo vadit chromium? The future directions of tanning. J Am Leather Chem Assoc. 2008;103(1):7-23. 
29. Qiang XH, Huang J, Zhang H. Study of tanning ability of the bisphenol S derivatives-Al(III) complex tanning agent. Leather Sci Eng. 2013;23(2):9-13.

30. Liu ZL, Zhang H, Qiang XH, Li M. Preparation and application of Si-Al complex tanning agent. China Leather. 2014;43(21):23-6.

31. Wu YB, Guan ZX, Zhang YX, Li QS. Development and application of twocomponent aluminum tanning agent. Gansu Sci Technol. 2016;32(20):65-8.

32. Qing TT, Chen XK, Wang XC, Sun S. Synthesis and application of hyperbranched polymer with terminal carboxyl groups-Al chrome-free tanning agent. Fine Chem. 2012;29(11):1098-102.

33. Xu XY, Tian C, Guo C, Li XR, Wang KY. Application of organic acid masked aluminum(III) complexes tanning agent in less chrome tanning. China Leather. 2013;42(7):1-4.

34. Xu W, Yin SW, Hao LF. Study on technology of Al-Gr combination tanning and alum pickling. J Shanxi Univ Sci Technol Nat Sci Ed. 2008;26(05):51-4.

35. Musa AE, Aravindhan R, Madhan B, Rao JR, Chandrasekaran B. Hennaaluminum combination tannage: a greener alternative tanning system. J Am Leather Chem Assoc. 2011;106(6):190-9.

36. Ding K, Taylor MM, Brown EM. Tanning effects of aluminum-genipin orvegetable tannin combinations. J Am Leather Chem Assoc. 2008;103(11): $377-82$.

37. Liu Y, Zhang JW, Mu SD, Long YR, Chen WY, Gu HB. Study on the hydrolysis and olation behaviors of aluminum sulfate under microwave irradiation. Leather Sci Eng. 2018;28(4):16-22.

38. Liu Y, Zhang JW, Chen WY, Astruc D, Gu HB. Microwave-irradiated tanning reaction of aluminum with collagen. J Appl Polym Sci. 2019;10:48682-92.

39. Lv XY. A brief discussion on manufacture of hide powder for tannin analysis. Chem Ind For Prod. 2000;20(1):71-4.

40. Liang FX, Huang RZ. Improvement of the computational formula for nontannin content in vegetable extracts. Chem Ind For Prod. 2014;34(3):13-21.

41. Manich AM, Cuadros S, Cot J, Carilla J, Marsal A. Determination of oxidation parameters of fatliquored leather by DSC. Thermochim Acta. 2005;429(2): 205-11.

42. Wu JC, Liao W, Zhang JW, Chen WY. Thermal behavior of collagen crosslinked with tannic acid under microwave heating. J Therm Anal Calorim. 2019;135(4):2329-35.

43. Li H, Chen HL, Luo R, Liu BL, Gao LZ. The interaction between collagen and an aluminum tanning agent. Macromol Biosci. 2003;3(7):344-6.

44. Zhong ZH, Li CM, Gu HF, Dou HL, Zhou LM. Effect of temperature on the secondary structure of fish scale collagen. Spectrosc Spectr Anal. 2007; 27(10):1970-6.

45. Long YR, Song B, Shi T, Liu T, Gu HB. AuNPs composites of gelatin hydrogels crosslinked by ferrocene-containing polymer as recyclable supported catalysts. J Appl Polym Sci. 2020;137(19):48653-65.

\section{Publisher's Note}

Springer Nature remains neutral with regard to jurisdictional claims in published maps and institutional affiliations.

\section{Submit your manuscript to a SpringerOpen ${ }^{\circ}$ journal and benefit from:}

- Convenient online submission

- Rigorous peer review

- Open access: articles freely available online

- High visibility within the field

- Retaining the copyright to your article

Submit your next manuscript at $\boldsymbol{\nabla}$ springeropen.com 